\title{
Mutation Causing von Willebrand's Disease in Scottish Terriers
}

\author{
Patrick J. Venta, Jianping Li, Vilma Yuzbasiyan-Gurkan, George J. Brewer, and William D. Schall
}

\begin{abstract}
Von Willebrand's Disease (vWD) in the Scottish Terrier breed is a serious, often fatal, hereditary bleeding disorder. Elimination of the mutated gene by selective breeding is an important goal for the health of this breed. Although the standard protein-based tests are accurate for identification of affected Scottish Terriers, they are not reliable for the identification of carriers of the mutant gene unless multiple replicate assays are performed. A simple, highly accurate test for carriers of the disease is needed so that veterinarians can counsel clients on which animals to use in their breeding programs. The complete coding region of von Willebrand factor (vWF) complementary DNA (cDNA) was sequenced from an affected animal, and a single base deletion in the codon for amino acid 85 of the prepro-vWF cDNA that leads to Scottish Terrier vWD was identified. A highly accurate polymerase chain reaction assay was developed that can distinguish homozygous normal animals from those that are homozygous affected or heterozygous. In a voluntary survey of 87 animals provided by Scottish Terrier owners, 15 were carriers and 4 were affected with vWD, 2 of which had previously been shown to have undetectable vWF. The determination of the complete canine vWF cDNA sequence should facilitate the identification of additional vWD alleles in other breeds and other species.
\end{abstract}

Key words: Bleeding disorder; Deletion; Dog; Genetic disease.

$\mathbf{V}^{\circ}$ on Willebrand's disease (vWD) is a bleeding disorder of variable severity that results from a quantitative or qualitative defect in von Willebrand factor (vWF).$^{1-5} \mathrm{vWD}$ has been observed in many mammalian species, including humans and dogs. This clotting factor has 2 known functions: (1) stabilization of factor VIII (anti-hemophilic factor A) in the blood and (2) aiding the adhesion of platelets to the subendothelium, which allows them to provide hemostasis more effectively. An affected individual may bleed severely if the factor is missing or defective.

The disease is the most common hereditary bleeding disorder in both dogs and humans, and it is genetically and clinically heterogeneous. Three clinical types, 1,2 , and 3 (formerly I, II, and $\mathrm{III}^{6,7}$ ), have been described. Type 1 vWD is thought to be inherited in a dominant, incompletely penetrant fashion in humans. In dogs, Type $1 \mathrm{vWD}$ appears to be inherited in a recessive fashion in at least some breeds, although it is possibly inherited as dominant with incomplete penetrance in others. Bleeding appears to be due to the reduced amount of $\mathrm{vWF}$ rather than a qualitative difference. Although type 1 is the most common form of $\mathrm{vWD}$ found in most mammals and can cause serious bleeding problems, it is generally less severe than the other 2 types.

Type 2 vWD patients have a qualitative defect in vWF, lacking high-molecular-weight multimers. Affected humans and dogs have a severe bleeding tendency. 2,5 Type $2 \mathrm{vWD}$ is inherited in a dominant fashion in humans but is inherited recessively in dogs. ${ }^{4,8}$

From the Departments of Small Animal Clinical Sciences (Venta, Yuzbasiyan-Gurkan, Schall) and Microbiology (Venta, YuzbasiyanGurkan), College of Veterinary Medicine, Michigan State University, East Lansing, MI; and the Department of Human Genetics University of Michigan, Ann Arbor, MI (Li, Brewer). Preliminary findings reported at the International Society for Animal Genetics meeting, 1996.

Reprint requests: Patrick J. Venta, PhD, Department of Small Animal Clinical Sciences, College of Veterinary Medicine, Michigan State University, East Lansing, MI 48824-1314; e-mail: venta@cvm. msu.edu.

Submitted September 8, 1998; Revised May 6, 1999; Accepted August 12, 1999.

Copyright (C) 2000 by the American College of Veterinary Internal Medicine

0891-6640/00/1401-0002/\$3.00/0
Type $3 v W D$ is the severest form of the disease. It is inherited as an autosomal recessive trait, and affected individuals have no detectable vWF in their blood. Serious bleeding episodes require transfusions of blood or cryoprecipitate to supply the missing vWF. Heterozygous carriers have moderately reduced factor concentrations but generally appear to have normal hemostasis.

Scottish Terriers appear to have only type 3 vWD. ${ }^{3,4}$ Homozygotes have no detectable $\mathrm{vWF}$ and have a severe bleeding disorder. Heterozygotes have reduced amounts of the factor and are clinically normal. ${ }^{9}$ The prevalence of vWD among Scottish Terriers including both heterozygotes and homozygotes has been variously estimated from $18 \%$ to $30 \% .^{9-11}$

Currently, detection of affected and carrier Scottish Terrier dogs is done by vWF antigen testing ${ }^{12,13}$ or historically by coagulation assays. ${ }^{14,15}$ These procedures yield variable results because the protein-based tests can be influenced by such things as sample handling, estrus, pregnancy, vaccination, age, and perhaps hypothyroidism. ${ }^{16-21} \mathrm{~A}$ dog that tests within the normal range on 1 day can test within the carrier range on another day. This variability makes it difficult for breeders to use this information to eliminate the disease-causing allele from their lines. Thus, it is highly desirable that a more definitive test be developed for Scottish Terriers.

Herein we report (1) the complete amino acid sequence as inferred from the canine vWF cDNA, (2) the discovery of the mutation that causes vWD in Scottish Terriers, and (3) the development of a simple direct DNA test for this mutation that distinguishes homozygous normal ("clear"), carrier, and affected animals with complete accuracy. This test gives breeders the potential to dramatically reduce the frequency of the disease-causing allele and the incidence of the disease within the Scottish Terrier breed. In addition, the determination of the complete nucleotide sequence of the canine vWF cDNA should lead to the rapid development of molecular tests for other breeds and for other species.

\section{Materials and Methods Isolation of RNA}

The source of the RNA was a uterus surgically removed because of pyometra from a Scottish Terrier affected with vWD (factor value $<$ 
$0.1 \%$ and a clinical bleeder). Total RNA was extracted from the tissues using Trizol. ${ }^{a}$ The integrity of the RNA was assessed by agarose gel electrophoresis on a $1 \times$ TBE $(1 \times$ TBE: $90 \mathrm{mM}$ Tris, $\mathrm{pH} 8.3,90 \mathrm{mM}$ borate, $1 \mathrm{mM}$ EDTA), $1 \%$ agarose gel and inspection of intact $18 \mathrm{~S}$ and $28 \mathrm{~S}$ ribosomal RNA bands. The factor values for the animals reported herein (always less than the sensitivity of the assay for those affected) were determined by the Diagnostic Laboratory at the College of Veterinary Medicine of Cornell University, by the Comparative Laboratory of Hematology at the State of New York Department of Public Health, or by Drs. Read and Brinkhaus and their colleagues at the University of North Carolina and were reported by the owners.

\section{Design of Polymerase Chain Reaction Primer Sets}

Polymerase chain reaction (PCR) primers were designed for use in 2 regions of the gene where sequences from 2 species were available. ${ }^{22,23}$ These primers were designed using rules for cross-species amplifications. ${ }^{24}$ Most of the primers had to be designed for other regions of the gene using the human sequence alone..$^{25}$ Primers were designed by taking into account number of codons per amino acid, relative amino acid mutabilities, and where applicable, conservation of nucleotide sequence. We used the same methodology to design a series of universal mammalian sequence tagged sites. ${ }^{24}$ Roughly $66 \%$ of the primers designed for the human sequence alone amplified the correct canine target. New primers had to be designed for regions that did not amplify with the original primer sets. After portions of the canine sequence had been determined, new primers were designed for the canine sequence. Primer sets and amplification conditions are available from the authors on request. Appropriate amplification conditions were determined using human and canine genomic DNAs for the initial primer sets. Generally, $94^{\circ} \mathrm{C}$ for 1 minutes, $57^{\circ} \mathrm{C}$ for $2 \mathrm{~min}-$ utes, and $72^{\circ} \mathrm{C}$ for 3 minutes for 35 cycles worked well with the majority of the amplifications. All amplifications used Tris- $\mathrm{HCl} \mathrm{pH} 8.3$ $\left(20^{\circ} \mathrm{C}\right), 50 \mathrm{mM} \mathrm{KCl}, 1.5 \mathrm{mM} \mathrm{MgCl}, 200 \mu \mathrm{M}$ dNTPs, and $20 \mu \mathrm{M}$ primers in 25 - or $100-\mu 1$ reactions.

\section{Reverse Transcriptase PCR}

Total RNA was reverse transcribed using random primers. ${ }^{26}$ Reverse transcription was performed using a commercially available kit ${ }^{\mathrm{b}}$ under the manufacturer's suggested conditions. Five microliters of reverse transcribed total RNA was included in each 50- $\mu$ l amplification reaction. The cDNA was amplified using the primer sets shown to work on canine genomic DNA.

\section{DNA Sequence Analysis}

Amplification products were isolated from agarose gels by adsorption onto silica gel particles using the manufacturer's method. ${ }^{c}$ Sequences were determined using ${ }^{32} \mathrm{P} 5^{\prime}$ end-labeled primers (the same ones used for the amplification) and a cycle sequencing kit. ${ }^{.}$The sequences of the $5^{\prime}$ and $3^{\prime}$ untranslated regions were determined after amplification using a RACE (random amplification of cDNA ends) kit. $^{\text {e }}$ Sequences were aligned using the Eugene software analysis package. ${ }^{f}$ The sequence of canine intron 4 was determined from PCRamplified genomic DNA. A "long PCR" kit was used to amplify this $5-\mathrm{kb}$ intron. ${ }^{\mathrm{b}}$

\section{Design of a Diagnostic Test}

PCR mutagenesis was used to create diagnostic and control BsiE I and Sau 96 I restriction enzyme sites for the test. Amplification conditions for the test are $94^{\circ} \mathrm{C}$ for 1 minute, $61^{\circ} \mathrm{C}$ for 1 minute, and $72^{\circ} \mathrm{C}$ for 1 minute for 50 cycles using cheek swab DNA ${ }^{27}$ (YuzbasiyanGurkan et al, unpublished). Twenty-five-microliter reactions were run, and $1 \mu l$ of restriction enzyme was added directly to the PCR reaction and incubated for 3 hours at $60^{\circ} \mathrm{C}$ for $B s i \mathrm{E}$ and $37^{\circ} \mathrm{C}$ for Sau $96 \mathrm{I}$. Eight microliters of each reaction were loaded onto a $3: 1$ NuSieve: low EEO agarose $1 \times$ TBE gel and run at $125 \mathrm{~V}$ for 1 hour. Gels were stained with ethidium bromide and photographed under 360-nM ultraviolet light.

\section{Population Survey}

A voluntary survey of Scottish Terriers was conducted to determine an estimate of the frequency of the mutation in the population. Participants were identified and enlisted through the efforts of members of the Scottish Terrier Club of America. All submitted samples was included in the survey. Previously determined factor values were not required, although some participants supplied values for their animals. DNA was collected from 87 Scottish Terriers from 16 pedigrees. DNA was isolated from blood using standard procedures ${ }^{28}$ or from cheek swab samples ${ }^{27}$ (Yuzbasiyan-Gurkan et al, unpublished). The genetic status of each animal in the survey was determined using the Bsi E I test.

\section{Results}

\section{Comparison of the Canine and Human Sequences}

The cDNA sequence has been placed in GenBank (accession no. AF099154). Two other groups have independently determined the canine vWF cDNA sequence and have also placed their sequences in GenBank (accession nos. L76227 and U66246). The alignment of the canine and human amino acid sequences is shown in Figure 1. There is $85.1 \%$ sequence identity between the prepro-vWF sequences of the canine and human amino acid sequences (Fig 1). The propeptide region is slightly less conserved than the mature protein $(81.4 \%$ versus $87.5 \%)$. There were no other noteworthy sequence identity differences in other regions of the gene or between the known repeats contained within the gene (data not shown).

Fourteen potential N-linked glycosylation sites are present in the canine sequence, all of which correspond to similar sites contained within the human sequence. The 2 integrin-binding sites identified in the human vWF protein sequence $^{29}$ also are conserved in the canine sequence (Fig 1). The $3^{\prime}$ untranslated region has diverged to a greater extent than the coding region (data not shown), a divergence comparable to that found between the human and bovine sequences derived for the $5^{\prime}$ flanking region..$^{30,31}$

Two other groups independently determined the sequence for most of exon 28..$^{32,33}$ All 3 sequences are in complete agreement, although we have also found 2 silent variants in other breeds (unpublished data). Partial sequences of exons 40 and 41 (cDNA nucleotides 6923-7155, from the initiation codon) were also independently determined by another group as part of the development of a polymorphic simple tandem repeat genetic marker. ${ }^{34}$ There is a single nucleotide sequence difference between this sequence (T) and ours (C) at nucleotide position 6928.

\section{Scottish Terrier $v$ WD Mutation}

A single base deletion was found in exon 4 (Fig 2). This frameshift mutation at codon 88 leads to a new stop codon 103 bases downstream. The resulting severely truncated protein of 119 amino acids does not include any of the mature von Willebrand factor region. The identity of the base in the normal allele was determined from an unaffected dog. 
Human MIPARFAGVLLALALILPGTLCAEGTRGRSSTARCSLFGSDEVNTFDGSMYSFAGYCSYL Dog -S-T-IVR-----------K--TK--V----M-----I-G--I----E-------D----

Human LAGGCQKRSESIIGDEQNGKRVSLSVYLGEFFDIHLFVNGTVTQGDQRVSMPYASKGLYL

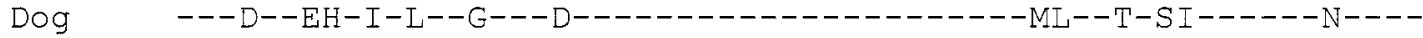

Human ETEAGYYKLSGEAYGEVARIDGSGNEQVLLSDRYENKTCGLCGNENI FAEDDFMTQEGTL

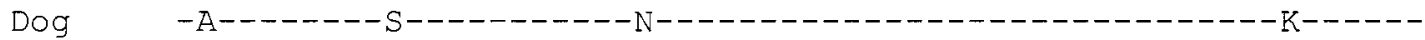

Human TSDPYDEANSWALSSGEQWCERASPPSSSCNISSGEMQKGLWEQCQLLKSTSVEARCHPL

Human YRQCVSPCARTCQSLHINEMCQERCVDGCSCPEGQLLDEGLCVESTECPCVHSGKRYPPG Dog $-\mathrm{KE}-----\mathrm{T}------\mathrm{VK}-\mathrm{V}---\mathrm{Q}-\cdots-----------\mathrm{H}--\mathrm{G}-\mathrm{A}--\mathrm{S}---\mathrm{A}-\mathrm{Q}-----$

Human TSLSRDCNTCICRNSQWICSNEECPGECLVTGQSHFKSFDNRYFTFSGICQYLLARDCQD

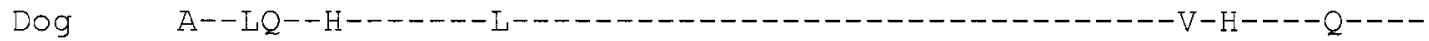

Human HSESIVIETVQCADDRDAVCTRSVTVRLPGLHNSLVKLKHGAGVAMDGQDVQLPLLKGDL Dog $-\mathrm{T}--\mathrm{V}---------\mathrm{L}------------\mathrm{H}--------\mathrm{N}-\mathrm{G}--\mathrm{S}-----\mathrm{I}-\mathrm{I}---\mathrm{Q}---$

Human RIQHTVTASVRLSYGEDLQMDWDGRGRLLVKLSPVYAGKTCGLCGNYNGNQGDDELTPSG Dog - - - - M-- - - - - - - - - S $-\mathrm{V}------\mathrm{T}-\mathrm{Y}-\mathrm{A}-------\mathrm{RG}------\mathrm{R}-\cdots-\mathrm{V}--\mathrm{A}-$

Human LAEPRVEDFGNAWKLHGDCQDLQKQHSDPCALNPRMTRFSEEACAVITSPTFEACHRAVS

Human PLPYLRNCRYDVCSCSDGRECLCGALASYAAACAGRGVRVAWREPGRCELNCPKGQVYLQ

Human CGTPCNLTCRSLSYPDEECNEACLEGCECPPGLYMDERGDCVPKAQCPCYYDGEIFOPED Dog $------\mathrm{M}--\mathrm{L}-\cdots--\mathrm{E}-\mathrm{D}-\cdots \mathrm{V}---\mathrm{S}--\mathrm{S}-\cdots-\mathrm{L}-----\cdots--------------$

Human IFSDHHTMCYCEDGEMHCTMSGVPGSLLPDAVLSSPLSHRSKRSLSCRPPMVKLVCPADN Dog

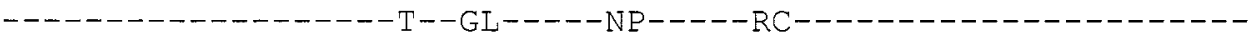

Human LRAEGLECTKTCQNYDLECMSMGCVSGCLCPPGMVRHENRCVALERCPCEHQGKEYAPGE Dog P-------A--------Q---T---------Q---------------------Q-----

Human TVKIGCNTCVCRDRKWNCTDHVCDATCSTIGMAHYLTFDGLKYLFPGECQYVLVQDYCGS

Human NPGTFRILVGNKGCSHPSVKCKKRVTILVEGGEIELEDGEVNVKRPMKDETHEEVVESGR

Human FGNSWKVSSQCADTRKVPLDSSPATCHNNIMKQTMVDSSCRILTSDVFODCNKLVDPEPY

Fig 1. Comparison of the human and canine prepropeptide vWF amino acid sequences. The asterisk indicates the location of the Scottish Terrier vWD mutation. Potential N-linked glycosylation sites are shown in bold. The known and postulated integrin-binding sites are boxed. Amino acid numbers based on the prepropeptide vWF sequence are shown on the right side of the figure. The mature protein begins at position 763 . The 
Human VAGRRFASGKKVTINPSDPEHCQICHCDVVNLTCEACQEPGGLVVPPTDAPVSPTTLYVE Dog -----L-P---II-----------N--G--E--K--R---SV------G-IGS--S---

Human DISEPPLHDFYCSRLLDLVELLDGSSRLSEAEEEVLKAFVVDMMERLRISQKWVRVAVVE

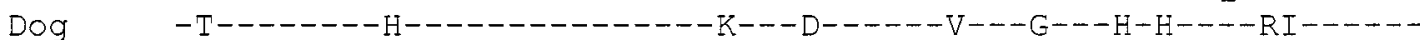

Human YHDGSHAYIGLKDRKRPSELRRIASQVKYAGSQVASTSEVLKYTLEQIESKIDRPEASRI Dog

Human ALLLMASQEPQRMSRNEVRYVQGLKKKKVIVIPVGIGPHANLKQIRLIEKQAPENKAEVL Dog

Human

Dog

Humar

Dog

Human

Dog

Human

Dog

Human

Dog

Human

Dog

Human

Dog

Human

Dog

Human

Dog

Human

Dog

Human

Dog

Human

Dog

Human

Dog

Human

Dog

Human

Dog

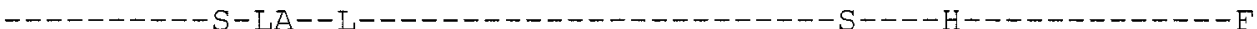

SSVDELEQQRDEIVSYLCDLAPEAPPPTLPPHMAQVTVGPGLLGVSTLGPKRNSMVLDVA $-\mathrm{G}------\mathrm{R}----\mathrm{IN}----------\mathrm{A}--\mathrm{QH}-\mathrm{P}-------\mathrm{SE}-----\mathrm{SP}-----------\mathrm{V}$

FVLEGSDKIGEADENRSKEFMEEVIQRMDVGQDS I HVTVLQYSYMVTVEYP ESEAQSKGD

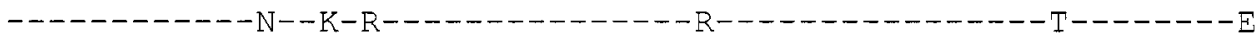

ILQRVREIRYQGGNRTNTGLALRYLSDHSFLVSQGDREQAPNLVYMVTGNPAS DEIKRLP $\mathrm{V}--\mathrm{Q}--\mathrm{D}---\mathrm{R}-----------\mathrm{Q}---\mathrm{E}---\mathrm{S}--------\mathrm{V}------------\cdots----\mathrm{M}-$

GDIQVVPIGVGPNANVQELERIGWPNAPILIQDEETLPREAPDLVLQRCCSGEGLQIPTL $------------\mathrm{H}-------\mathrm{K}----------\mathrm{H}---\mathrm{M}------------------------$

SPAPDCSQPLDVILLLDGSSSFPASYFDEMKSFAKAFISKANIGPRLTQVSVLQYGSITT

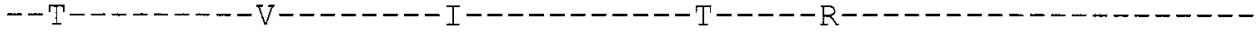

IDVPWNVVPEKAHLLSIVDVMQREGGPSQIGDALGEAVRYLTSEMHGARPGASKAVVILV $-------A Y--V----\cdots--I--Q-\cdots---E-----S-----V---V---------------$

TDVSVDSVDAAADAARSNRVTVFPIGIGDRYDAAQLRILAGPAGDSNVVKLQRIEDLPTM $----------E---------------S E---S S----K A G--M-R---------V$

VTLGNSFLHKLCSGFVRICMDEDGNEKRPGDVWTLPDQCHTVTCQPDGQTLLKTHRVNCD A------F-------D $-\mathrm{V}-\mathrm{V}----------------------\mathrm{L}--------\mathrm{S}-\cdots---$

RGLRPSCPNSQSPVKVEETCGCRWTCPCVCTGSSTRHIVTEDGQNEKLTGSCSYVLFQNK

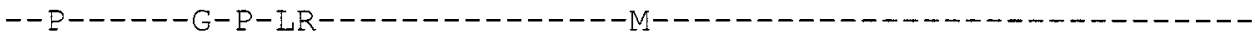

EQDLEVIIHNGACS PGARQGCMKS IEVKHSALSVELHSDMEVTVNGRLVSVPYVGGNMEV

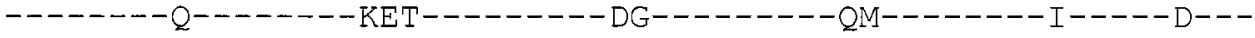
$----\mathrm{T}--Y--------------------------\mathrm{R}---------------------1---$

2160 $-------A-I------Q \mathrm{Q}-\mathrm{K}-\mathrm{S}--\mathrm{VH}----\mathrm{P}-\mathrm{SEEE}------\mathrm{SE}---------------$

2220 AICQODSCHOEQVCEVIASYAHLCRTNGVCVDWRTPDFCAMSCPPSLVYNHCEHGCPRHC $-\mathrm{M}--\mathrm{P}----\mathrm{PKK}---\mathrm{A}--\mathrm{L}-------\mathrm{K}-------\mathrm{RAN}--------------------\mathrm{L}-$ DGNVSSCGDHPSEGCECPPDKVMLEGSCVPEEACTQCIGEDGVQHQFLEAWVPDHQPCQI $\mathrm{E}--\mathrm{T}-\cdots--\mathrm{Q}-\cdots-\cdots---\mathrm{NQ}--------\cdots-----\mathrm{S}----\mathrm{R}-----\mathrm{T}---\mathrm{A}------$

CTCLSGRKVNCTTQPCPTAKAPTCGLCEVARLRQNADQCCPEYECVCDPVSCDLPPVPHC 2340

Fig 1. (continued) human sequence is derived from GenBank accession no. X04385. ${ }^{46}$ The canine nucleotide sequence has been deposited in GenBank (accession no. AF099154). 


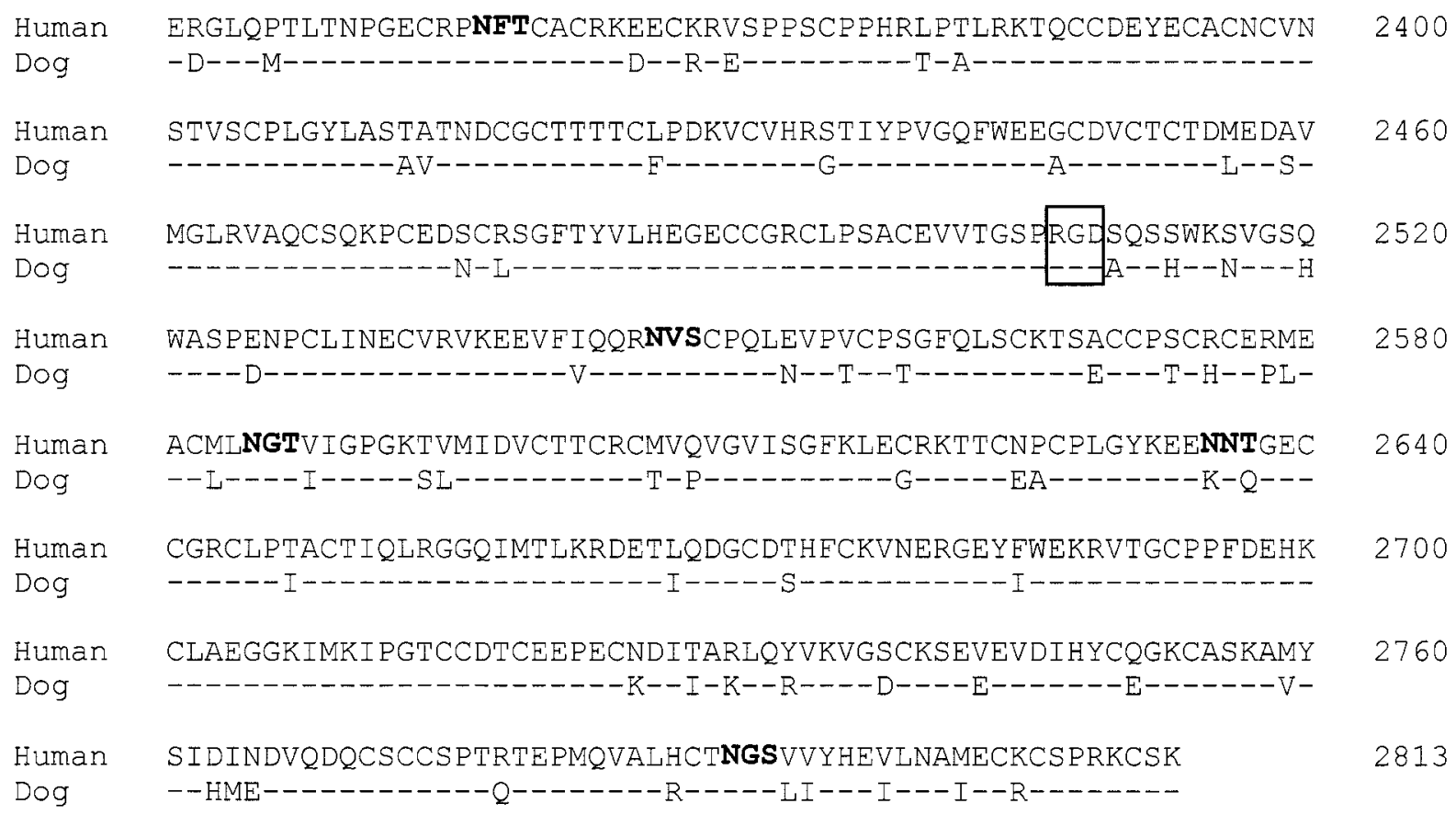

Fig 1. Continued.

\section{Development of a Diagnostic Test}

A PCR primer was designed to produce a $B s i \mathrm{E}$ I site in the mutant allele but not in the normal allele (Fig 3). To ensure that the restriction enzyme cut the amplified DNA to completion, an internal control restriction site common to both alleles was designed into the nondiagnostic primer. The test was verified by digestion of the DNA from animals that were affected, obligate carriers, or normal (based on reports of factor values $>100 \%$ of normal from commonly used testing labs and reported to us by the owners and from breeds in which type 3 vWD has not been observed). The expected results were obtained (e.g., Fig 4). Five vWDaffected animals from a colony of mixed-breed dogs founded from Scottish Terriers ${ }^{35}$ were homozygous for this mutation. An additional unaffected animal from this same colony was clear.

It would still be possible to misinterpret the results of the test if restriction enzyme digestion were incomplete and if the rates of cleavage of the control and diagnostic sites were vastly different. The rates of cleavage of the $2 \mathrm{Bsi} \mathrm{E}$ I sites were examined by partially digesting the PCR products and running them on capillary electrophoresis. The rates were nearly equal (the diagnostic site is cut $12 \%$ faster than the control site).

The mutagenesis primer was also designed to produce a Sau96 I site in the normal allele but not the mutant allele. This test is the reverse of the $B s i \mathrm{E}$ I-dependent test with respect to which allele is cut. Natural internal Sau96 I sites serve as digestion control sites (shown in Fig 3). The test using this enzyme produced genotypic results identical to those using $B s i \mathrm{E}$ I for all animals examined (data not shown).

\section{Mendelian Inheritance}

Three pedigrees were examined in which the normal and mutant alleles were segregating. The alleles, as typed by both the BsiE I and Sau96 I tests, showed no inconsistencies with Mendelian inheritance. One of these pedigrees included 2 affected animals, 2 phenotypically normal siblings, and the obligate carrier parents. The 2 parents were found to be heterozygous by the test, the 2 affected animals were found to be homozygous for the mutant allele, and the normal siblings was found to be heterozygotes (Fig 4).

\section{Population Survey for the Mutation}

Cheek swabs or blood samples were collected from 87 animals to determine the prevalence of carriers in the US Scottish Terrier population. Although we attempted to make the sample as random as possible, the results of the tests revealed that these dogs came from 16 pedigrees, several of which were distantly interconnected. This close connection is due to some ascertainment bias based on ownership (as opposed to phenotypic ascertainment bias). In these 87 animals, we found 4 affected and 15 carrier animals.

\section{Discussion}

The determination of the canine vWF cDNA sequence permits the first comparison between 2 complete inferred mammalian vWF protein sequences. The protein has a structure based on 4 kinds of repeat units: the A, B, C, and $D$ repeats, ${ }^{1,2}$ There does not appear to be a strict correspondence between these repeat units and the intron-exon structure of the gene. The most notable feature of the gene is the large exon 28, which contains most of the $3 \mathrm{~A}$ repeat units. Although most human type 2 mutations occur in this 


\section{Clear Carrier Affected}

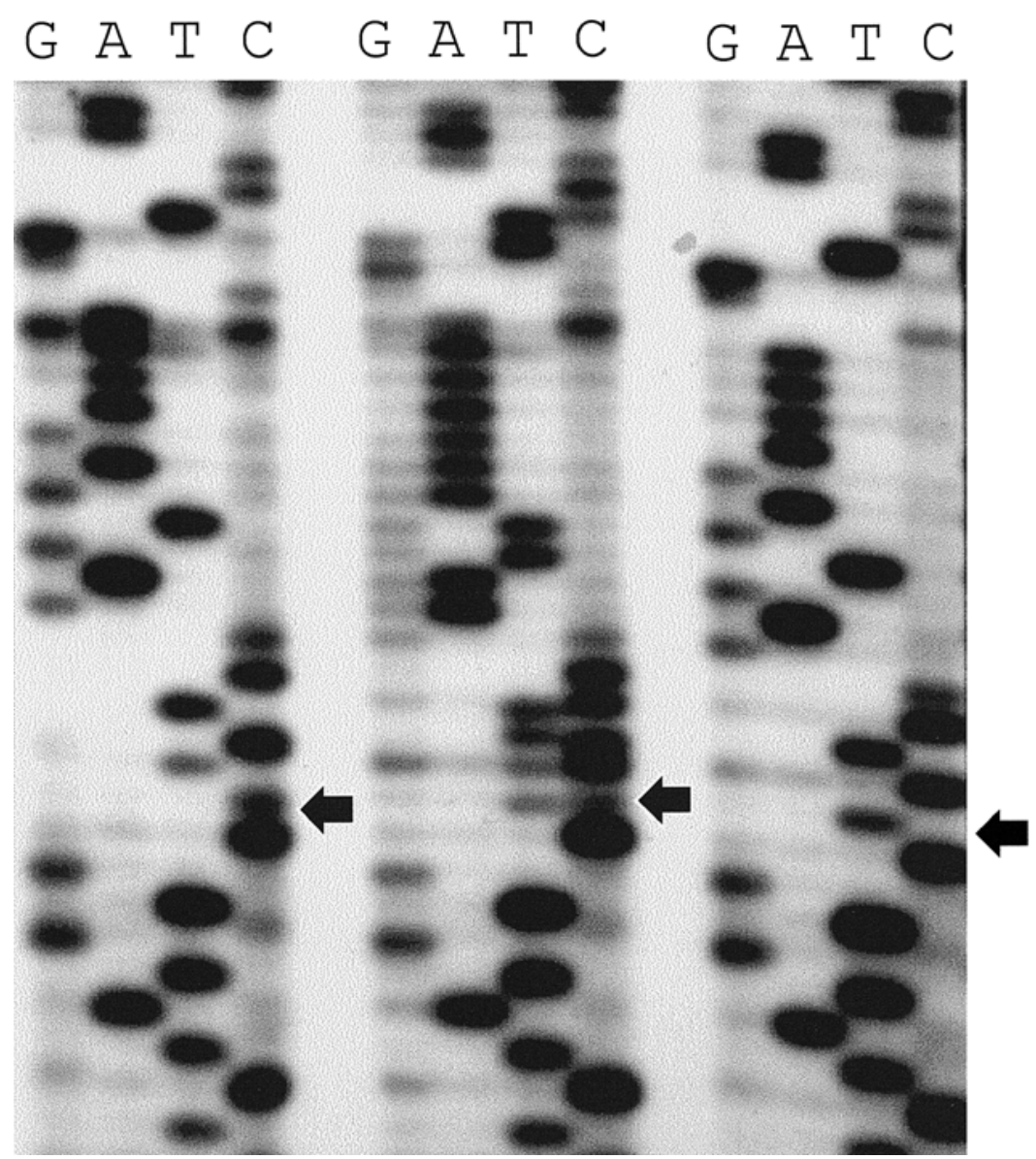

Fig 2. Nucleotide sequencing ladders for the vWD mutation region for clear, carrier, and affected Scottish Terriers. The sequences were obtained directly from PCR products derived from genomic DNA in exon 4. The arrowheads show the location of the C nucleotide that is deleted in the disease-causing allele. The carrier ladder of each base above the point of the mutation has a doublet appearance, as predicted for deletion mutations. The factor values reported by the owners of these Scottish Terriers were $54 \%$ clear, $34 \%$ carrier, and $<0.1 \%$ affected.

exon, type 3 mutations seem to have a relatively random distribution over the entire length of the gene. Although we have not determined the entire intron-exon structure of the canine gene, the few intron splice sites that we have determined are suggest that the human and canine gene structures are very similar (unpublished results).

The order and length of these repeats has remained conserved between the 2 species. There are no inserted or deleted amino acids, and thus the lengths of the human and canine prepropeptide sequences are identical at 2,813 amino acids. The integrin receptor sites of the human factor are both conserved in the canine molecule (Fig 1). All of the 234 cysteine residues are conserved between the 2 species, suggesting that these residues are of importance for the maintenance of the structure of the molecule. The determination of the canine sequence will also allow cross-species PCR amplifications to be conducted more easily, which should lead to a greater understanding of the structure, function, and evolution of this important coagulation protein.

The results reported here also establish that the single base deletion found in exon 4 of the vWF gene causes vWD in the Scottish Terrier breed. The putative protein produced from the mutant allele is extremely short and does not include any of the mature vWF protein. Four Scottish Terriers known to be affected with the disease were homozygous for the mutation. Five other mixed-breed dogs descended from Scottish Terriers and affected with vWD were also homozygous for the mutation. No phenotypically normal animals were homozygous for the mutation. Unaffected obligate carriers are always heterozygous for the mutation.

The gene frequency in the population surveyed appears to be around 0.13 , resulting in a heterozygote frequency of about $23 \%$ and expected frequency of affected animals of about $2 \%$. It is extremely difficult to obtain truly random samples from domestic animal populations, and thus caution is needed in extrapolating the results from the survey conducted in this report to the whole Scottish Terrier population. Although the sample size is relatively small and probably biased in unknown ways, these data are in general agreement with the results of protein-based surveys ${ }^{5,10}$ and demonstrate that the mutant allele is not uncommon.

The data collected so far indicate that this mutation could account for most and possibly all of the vWD found in 


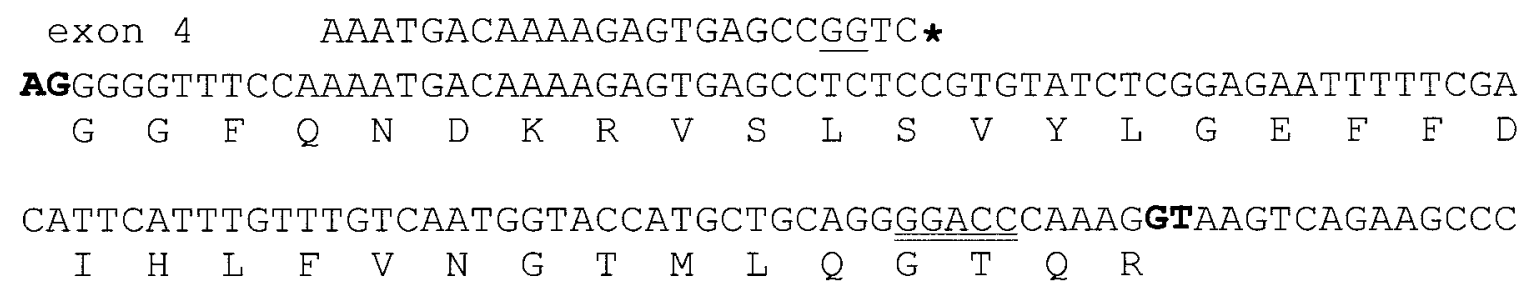

GAATGTTCAGGTTAATATGGACCCTGGGGATCACTTTGCAACCCCCTTGTTTTTTCAGAT

GAGGGAGCCGGGGCCCAGAGACAGGAAGTAAATGTGCCCAGGGAAAGTGAGTGGCAGGAC

TGGGTGAAAGCCCCATATCCCGACTCCTGGTCAAGGAGACTTTGCACCAAGGTCCCAGCC 3'-GGGCTGGCGACCAGTTCCTCTGAA-5'

CTGGAGCATGGGGTTGGGGTTGGAAGGTGGAGGGACATGGAGGAAATGCATGAGAAGCAC

exon 5
GCTTCCTGAGCTCCTCCTTGTCCCACCAGCATCTCCATGCCCTACGCCTCCAATGGGC
I $S$ S M $P$ Y A S N G

Fig 3. Molecular test to detect the Scottish Terrier vWD mutation. An asterisk indicates the position of the deleted nucleotide. BsiE I restriction sites were created by PCR primer mutagenesis. The altered nucleotides in each primer are underlined. The normal and mutant allele can also be distinguished using Sau96 I. The naturally occurring Sau96 I sites are shown by double underlines. The highly conserved donor and acceptor dinucleotide splice sequences are shown in bold.

Scottish Terriers. This result is consistent with the allelic homogeneity found for other genetic diseases of domestic animals that have been defined at the molecular level. ${ }^{36-38}$ This homogeneity is most likely due to the pronounced founder effect (usually popular sire effect) that occurs in domestic animals, in contrast to the situation in most human and wild animal populations.

Other vWD alleles may exist or may occasionally arise in the Scottish Terrier breed. However, several facts suggest that the mutation described in the current report accounts for most of the disease in the breed: (1) the number of carriers of this mutation is of the same magnitude as that found in previous protein-based surveys, ${ }^{4,9,10}$ which would be consistent with the characterization of this mutation as the major mutation; (2) all of the results obtained in this study are explained by the 1 mutation; (3) only type 3 vWD has ever been reported in Scottish Terriers, which supports the probability of allelic homogeneity; and (4) the founder effect is known to be an important element in domestic animal genetic diseases. Although there is still a possibility that other vWD alleles exist at low frequency in the Scottish Terriers, it seems likely that the elimination of this $1 \mathrm{mu}-$ tation would cause vWD to become a rare disease in the breed.

Published data using the protein-based factor assays have shown that, at least in several instances, obligate carriers have had factor values that would lead to a diagnosis of "clear" of the disease allele. For example, in 1 study an obligate carrier had a factor value of $78 \% .{ }^{39}$ In another study, at least some of the obligate carriers had factor values of $\geq 65 \%{ }^{35}$ In both of these studies, however, research- ers used older methodologies (Laurell electrophoresis and venom coagulation), although even enzyme-linked immunosorbent assays can produce results with considerable variation. ${ }^{40}$ In addition, the number of animals that fall into an equivocal range can be substantial. In 1 study, $19 \%$ of Scottish Terriers fell in this range (50-65\% of the normal vWF antigen value). ${ }^{10}$ Thus, although the protein-based tests have been useful, the certainty of the DNA-based test should relieve the necessity of repeated testing and the variability associated with the protein-based assays. In a recent report, the authors provided evidence that daily biological variability is more important than the variability found in the test, and they stated that "multiple tests may be necessary to obtain a reliable estimate of vWF concentration in dogs." 40

A direct test for the mutation should also be more useful than a linkage-based test using a vWF-specific polymorphic site, such as the known microsatellite marker contained within intron 40 of the canine vWF gene, ${ }^{34}$ because the mutation will probably be present on only a proportion of chromosomes that have a particular allele of the microsatellite. Although linkage disequilibrium between the mutation and 1 of the alleles may exist, there will still be many dogs with the same repeat number that do not have the mutation. In addition, a rare recombination between the mutation and the marker or a mutation in the microsatellite repeat could affect the accuracy of the diagnosis.

Although it should also be possible to deduce the genotypic status of the animal using family information, this method is less reliable than a direct test because it requires obtaining accurate information about relatives, which is of- 


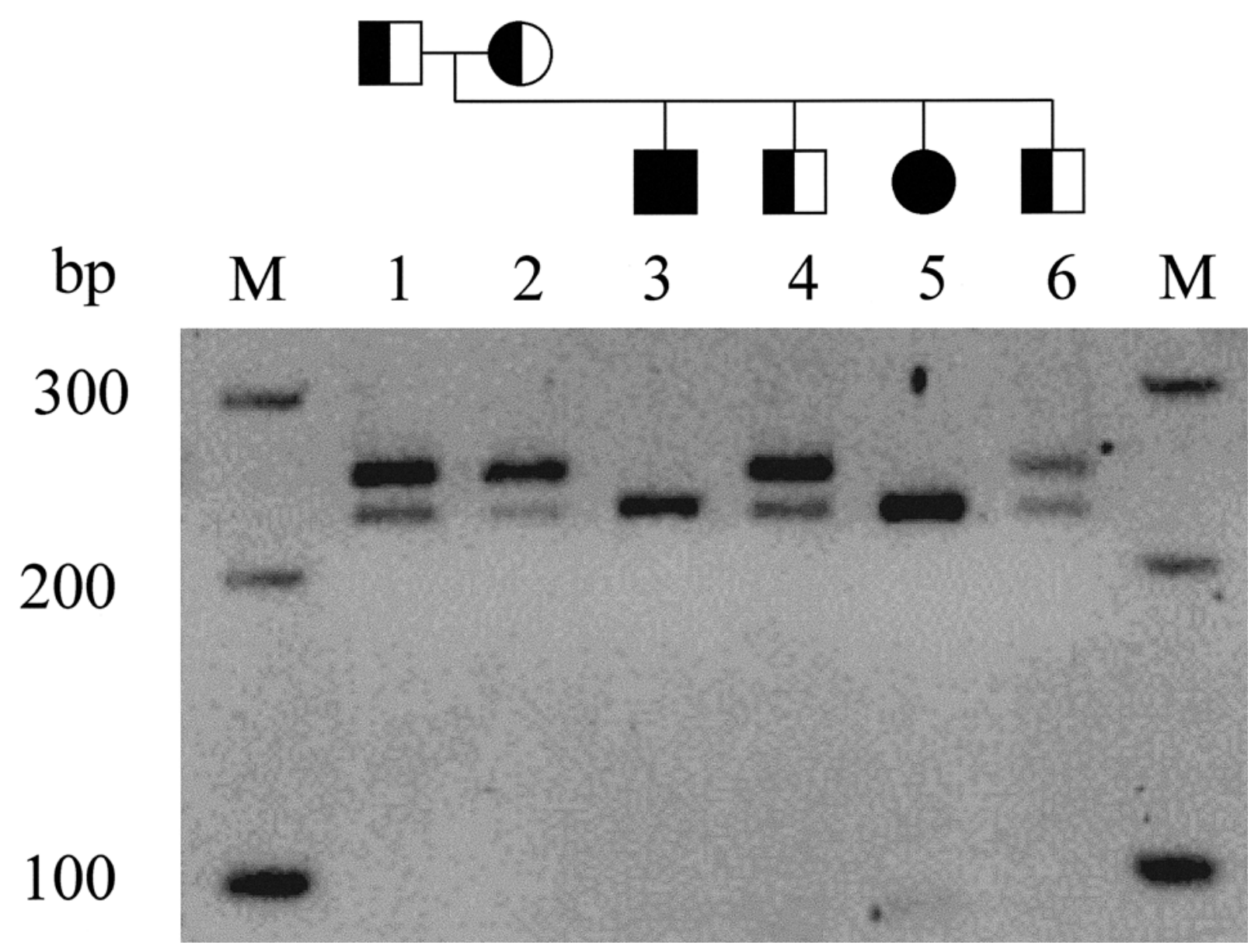

Fig 4. Scottish Terrier pedigree showing segregation of the mutant and normal vWF alleles. Exon 4 of the vWF gene was amplified from genomic DNA using PCR techniques. The PCR products were examined for the presence of the normal and mutant vWF alleles by agarose gel electrophoresis after digestion with BsiE I (see Fig 3). The affected animals are homozygous for the mutant allele (229 bp; lanes 3, 5). The other animals in this pedigree are heterozygotes (251 bp and 229 bp; lanes 1, 2, 4, 6), including the obligate carrier parents. One hundred base-pair ladders were run in the marker lanes $(\mathrm{M})$.

ten not possible. Genetic counseling using a linkage-based test requires considerably more effort, both on the part of the veterinarian or breeder and the service provider, than does analysis of blood or cheek swabs. Also, linkage-based tests do not consistently allow the determination of the genotype at the disease locus, often because the marker is not informative. ${ }^{41}$

The Scottish Terrier mutation is present in the propeptide portion of the vWF molecule. The propeptide is removed prior to delivery of the mature protein into the plasma. The propeptide is also important for the assembly of the multimeric mature vWF protein. ${ }^{42,43}$ With the Scottish Terrier frameshift $\mathrm{vWD}$ mutation, neither the propeptide nor any of the mature factor would ever be produced. To our knowledge, no factor has ever been detected in the blood of affected Scottish Terriers, as predicted for the frameshift mutation that was identified.

The determination of the complete canine vWF cDNA sequence will have an impact upon the development of carrier tests for other breeds and other species. Currently, Shetland Sheepdogs and Dutch Kooikers are known to have a significant amount of type 3 vWD.,944 Type 3 vWD also has occasionally been seen in other breeds. ${ }^{39}$ All type $3 \mathrm{vWD}$ mutations described in humans to date have been found within the vWF gene itself. The availability of the canine sequence will make it easier to find the mutations in other breeds. The mutation for the Dutch Kooiker breed has been recently reported. ${ }^{44}$ In addition, at least some type $1 \mathrm{mu}-$ tations have been found within the human vWF gene, and thus type 1 mutations may be found within the canine vWF gene for breeds affected with that form of the disease. The availability of 2 divergent mammalian vWF cDNA sequences will also make it much easier to sequence the gene from other mammalian species using cross-species PCR methods. ${ }^{24,45}$

The test that we have developed for the detection of the mutation in Scottish Terriers can be perfprmed using only small amounts of DNA from any tissue. The tissues that can be obtained using the least invasive methods are blood and buccal cells. A cheek swab can be easily obtained by the veterinarian or the breeder.

Care should be taken not to produce genetic bottlenecks when using results from this test. The production of affected animals can be avoided by using at least 1 clear animal in a mating. Genes conferring desirable characteristics in carrier animals can be maintained in a line until 
the disease-causing allele is lost after a few generations. Using this approach, genetic variability will be maintained at other loci, and the potential detrimental effects of stringent selection against a deleterious gene will be avoided.

\section{Footnotes}

${ }^{a}$ Life Technologies, Gaitherburg, MD

${ }^{\mathrm{b}}$ Boehringer-Mannheim, Indianapolis, IN

' Qiagen, Chatsworth, CA

d United States Biochemical Corp, Cleveland, OH

${ }^{\mathrm{e}}$ Marathon, Clontech, Palo Alto, CA

${ }^{\mathrm{f}}$ Lark Technologies, Houston, TX

\section{Acknowledgments}

We thank Murat Gurkan, Paul Ferguson, Dr Yueying Cao, and Chris Willett for conducting some of the experiments for this work and Dr Mary A. McLoughlin, Dr Stephen P. DiBartola, Ms Helen Harbulak, Dr Majorie S. Read, Dr Kenneth M. Brinkhous, and Mrs Barbara DeSaye. This work was supported by the American Kennel Club, the Orthopedic Foundation for Animals, the Morris Animal Foundation, and the Companion Animal Fund at Michigan State University and by contributions from Scottish Terrier clubs and owners.

Some of the authors (GJB, PJV, VYG) have equity in the technology transfer company that they founded to provide the $\mathrm{vWD}$ test and other molecular genetic services to veterinarians and dog breeders.

\section{References}

1. Ginsburg D, Bowie EJW. Molecular genetics of von Willebrand disease. Blood 1992;79:2507-2519.

2. Ruggeri ZM, Ware J. Von Willebrand factor. Fed Am Soc Exp Biol J 1993;7:308-316.

3. Dodds WJ. Von Willebrand's disease in dogs. Mod Vet Pract 1984;56:681-686.

4. Johnson GS, Turrentine MA, Kraus KH. Canine von Willebrand's disease: A heterogeneous group of bleeding disorders. Vet Clin North Am Small Anim Pract 1988;18:195-229.

5. Brooks M. Management of canine von Willebrand's disease. Prob Vet Med 1992;4:636-646.

6. Sadler JE, Gralnick HR. Commentary: A new classification for von Willebrand disease. Blood 1994;84:676-679.

7. Sadler JE, Matsushita T, Dong Z, et al. Molecular mechanism and classification of von Willebrand disease. Thromb Haemostasis 1995;74:161-166.

8. Brooks M, Raymond S, Catalfamo J. Severe, recessive von Willebrand's disease in German Wirehaired Pointers. J Am Vet Med Assoc 1996;209:926-929.

9. Brooks M, Dodds WJ, Raymond SL. Epidemiologic features of von Willebrand's disease in Doberman Pinschers, Scottish Terriers, and Shetland Sheepdogs: 260 cases (1984-1988). J Am Vet Med Assoc 1992;200:1123-1127.

10. Stokol T, Parry BW, Mansell PD. Von Willebrand's disease in Scottish Terriers in Australia. Aust Vet J 1995;72:404-407.

11. Green RA, Thomas JS. Hemostatic disorders: Coagulopathies and thrombosis. In: Ettinger SJ, Feldman EC, eds. Textbook of Veterinary Internal Medicine, 4th ed. Philadelphia PA: WB Sanders; 1995:1946-1963.

12. Brooks M, Raymond S, Catalfamo J. Plasma von Willebrand factor antigen concentration as a predictor of von Willebrand's disease status in German Wirehaired Pointers. J Am Vet Med Assoc 1996; 209:930-933.

13. Slappendel RJ, Frielink RA, Mol JA, et al. An enzyme-linked immunosorbent assay (ELISA) for von Willebrand factor antigen (vWf-Ag) in canine plasma. Vet Immunol Immunopathol 1992;33: $145-154$.

14. Rosborough TK, Johnson GS, Benson RE, et al. Measurement of canine von Willebrand factor using ristocetin and Polybrene. J Lab Clin Med 1980;96:47-56.

15. Read MS, Potter JY, Brinkhous KM. Venom coagglutinin for detection of von Willebrand factor activity in animal plasmas. J Lab Clin Med 1983;101:74-82.

16. Strauss HS, Diamond LK. Elevation of factor VIII (antihemophilic factor) during pregnancy in normal persons and in a patient with von Willebrand's disease. N Engl J Med 1963;269:1251-1252.

17. Bloom AL. Von Willebrand factor: Clinical features of inherited and acquired disorders. Mayo Clin Proc 1991;66:743-751.

18. Stirling Y, Woolf L, North WRS, et al. Haemostasis in normal pregnancy. Thromb Haemostasis 1984;52:176-182.

19. Mansell PD, Parry BW. Changes in factor VIII activity and von Willebrand factor antigen concentration with age in dogs. Br Vet $\mathrm{J}$ 1992;148:329-337.

20. Avgeris S, Lothrop CD, McDonald TP. Plasma von Willebrand factor concentration and thyroid function in dogs. J Am Vet Med Assoc 1990;196:921-924.

21. Panciera DP, Johnson GS. Plasma von Willebrand factor antigen concentration in dogs with hypothyroidism. J Am Vet Med Assoc 1994;205:1550-1553.

22. Lavergne JM, Piao YC, Ferreira V, et al. Primary structure of the factor VIII binding domain of human, porcine and rabbit von Willebrand factor. Biochem Biophys Res Commun 1993;194:1019-1024.

23. Bakhshi MR, Myers JC, Howard PS, et al. Sequencing of the primary adhesion domain of bovine von Willebrand factor. Biochim Biophys Acta 1992;1132:325-328.

24. Venta PJ, Brouillette JA, Yuzbasiyan-Gurkan V, et al. Genespecific universal mammalian sequence-tagged sites: Application to the canine genome. Biochem Genet 1996;34:321-341.

25. Mancuso DJ, Tuley EA, Westfield LA, et al. Human von Willebrand factor gene and pseudogene: Structural analysis and differentiation by polymerase chain reaction. Biochemistry 1989;30:253269.

26. Bergenhem NCH, Venta PJ, Hopkins PJ, et al. Mutation creates an open reading frame within the $5^{\prime}$ untranslated region of macaque erythrocyte carbonic anhydrase (CA) I mRNA that suppresses CA I expression and supports the scanning model for translation. Proc Natl Acad Sci USA 1992;89:8798-8802.

27. Richards B, Skoletsky J, Shuber AP, et al. Multiplex PCR amplification from the CFTR gene using DNA prepared from buccal brushes/swabs. Hum Mol Genet 1992;2:159-163.

28. Sambrook J, Fritsch EF, Maniatis T. Molecular Cloning: A Laboratory Manual, 2nd ed. Cold Spring Harbor, NY: Cold Spring Harbor Laboratory; 1989:914.

29. Lankhof H, Wu Y, Vink T, et al. Role of the glycoprotein Ibbinding A1 repeat and the RGD sequence in platelet adhesion to human recombinant von Willebrand factor. Blood 1995;86:1035-1042.

30. Janel N, Schwachtgen JL, Bakhshi MR, et al. Comparison of the $5^{\prime}$-flanking sequences of the human and bovine von Willebrand factor-encoding genes reveals alternation of highly homologous domains with species-specific Alu-type repeats. Gene 1995;167:291-295.

31. Meyer D, Girma JP. von Willebrand factor: Structure and function. Thromb Haemostasis 1993;70:99-104.

32. Mancuso DJ, Christopherson PA, Montgomery RR. An homologous canine von Willebrand factor binding domain for glycoprotein 1b. Thromb Haemostasis 1993;69:980.

33. Porter CA, Goodman M, Stanhope MJ. Evidence on mamma- 
lian phylogeny from sequences of exon 28 of the von Willebrand factor gene. Mol Phylogenet Evol 1996;5:89-101.

34. Shibuya H, Collins BKE, Huang HM, Johnson GS. A polymorphic (AGGAAT) $)_{n}$ repeat in an intron of the canine von Willebrand factor gene. Anim Genet 1994;24:122.

35. Brinkhous KM, Read MS, Reddick RL, Griggs TR. Pathophysiology of platelet-aggregating von Willebrand factor: Applications of the venom coagglutinin vWF assay. Ann NY Acad Sci 1991;370:191203.

36. Shuster DE, Kehrli ME, Ackermann MR, Gilbert RO. Identification and prevalence of a genetic defect that causes leukocyte adhesion deficiency in Holstein cattle. Proc Natl Acad Sci USA 1992; 89:9225-9229.

37. Rudolph JA, Spier SJ, Byrns G, et al. Periodic paralysis in Quarter Horses: A sodium channel mutation disseminated by selective breeding. Nat Genet 1992;2:144-147.

38. O'Brien PJ, Shen H, Cory CR. Use of a DNA-based test for the mutation associated with porcine stress syndrome (malignant hyperthermia) in 10,000 breeding swine. J Am Vet Med Assoc 1993; 203:842-851.

39. Johnson GS, Lees GE, Benson RE, et al. A bleeding disease (von Willebrand's disease) in a Chesapeake Bay Retriever. J Am Vet Med Assoc 1980;176:1261-1263.

40. Moser J, Meyers KM, Meinkoth JH, Brassard JA. Temporal variation and factors affecting measurement of canine von Willebrand factor. Am J Vet Res 1996;57:1288-1293.

41. Yuzbasiyan-Gurkan V, Halloran Blanton S, Cao Y, et al. Linkage of a microsatellite marker to the canine copper toxicosis gene in the Bedlington Terrier. Am J Vet Res 1997;58:23-27.

42. Verweij L, Hart M, Pannekoek H. Expression of variant von Willebrand factor (vWF) cDNA in heterologous cells: Requirement of the pro-polypeptide in vWF multimer formation. Eur Mol Biol Org J 1987;6:2885-2890.

43. Wise RJ, Pittman DD, Handin RI, et al. The propeptide of von Willebrand factor independently mediates the assembly of von Willebrand multimers. Cell 1988;52:229-236.

44. Slappendel RJ. Von Willebrand's disease in Dutch Kooiker dogs. Vet Q 1995; 17:S21-S22.

45. Bonthron D, Orr EC, Mitsock LM, et al. Nucleotide sequence of pre-pro-von Willebrand factor cDNA. Nucleic Acids Res 1986;14: $7125-7128$

46. Venta PJ, Yuzbasiyan-Gurkan V, Schall WD, Brewer GJ. Identification of a single base deletion that causes Scottish Terrier von Willebrand's disease. Anim Genet 1996;27(Suppl 2):49. 